\title{
LA-UR-13-28223
}

Approved for public release; distribution is unlimited.

Title: $\quad$ Module 8: Godiva-IV Critical Assembly Demonstration

$\begin{array}{ll}\text { Author(s): } \quad & \text { Goda, Joetta M. } \\ & \text { Bounds, John Alan } \\ & \text { Myers, William L. } \\ & \text { Sanchez, Rene G. }\end{array}$

Intended for: $\quad$ NCSP Training Class Notes

Web

Issued: $\quad$ 2013-10-24

Disclaimer:

Los Alamos National Laboratory, an affirmative action/equal opportunity employer,is operated by the Los Alamos National

Security, LLC for the National NuclearSecurity Administration of the U.S. Department of Energy under contract DE-AC52-06NA25396.

By approving this article, the publisher recognizes that the U.S. Government retains nonexclusive, royalty-free license to publish or reproduce the published form of this contribution, or to allow others to do so, for U.S. Government purposes.

Los Alamos National Laboratory requests that the publisher identify this article as work performed under the auspices of the

U.S. Departmentof Energy. Los Alamos National Laboratory strongly supports academic freedom and a researcher's right to publish; as an institution, however, the Laboratory does not endorse the viewpoint of a publication or guarantee its technical correctness. 


\section{Module 8 Godiva-IV Critical Assembly Demonstration}




\section{Goals}

- To ensure trainees gain a working knowledge of the Godiva IV assembly, including its

- design,

- intent, and

- controls.

- To ensure trainees gain a working knowledge of how to use the Inhour equation and associated parameters for the Godiva IV assembly to infer the reactivity addition during a transient excursion.

- To ensure trainees gain a working knowledge of the differences between subcritical, delayedcritical, and prompt-critical operations.

- To ensure the trainees gain a working knowledge of the concept of temperature-dependent reactivity feedback as it applies to the transient behavior of a critical assembly during a nuclear excursion.

- To ensure the trainees gain a basic working knowledge of how Godiva IV steady-state and prompt-critical operations are conducted. 


\section{Enabling Objectives}

- (EO1) Trainees will illustrate a physical description of the Godiva IV assembly.

- (EO2) Trainees will recall how to infer reactivity addition from a measurement of the positive reactor period.

- (EO3) Trainees will describe the difference between subcritical, delayed-critical, and prompt-critical operations.

- (EO4) Trainees will explain the effect of temperature-dependent reactivity feedback on the transient behavior of a critical assembly.

- (EO5) Trainees will recall the basic controls and operations associated with the Godiva IV assembly, including the

- assembly sequence for a "free-run" excursion,

- assembly sequence for a prompt-critical burst operation, and

- system interlocks. 


\section{Godiva IV Assembly Description ${ }^{1,2,3}$ (EO1)}

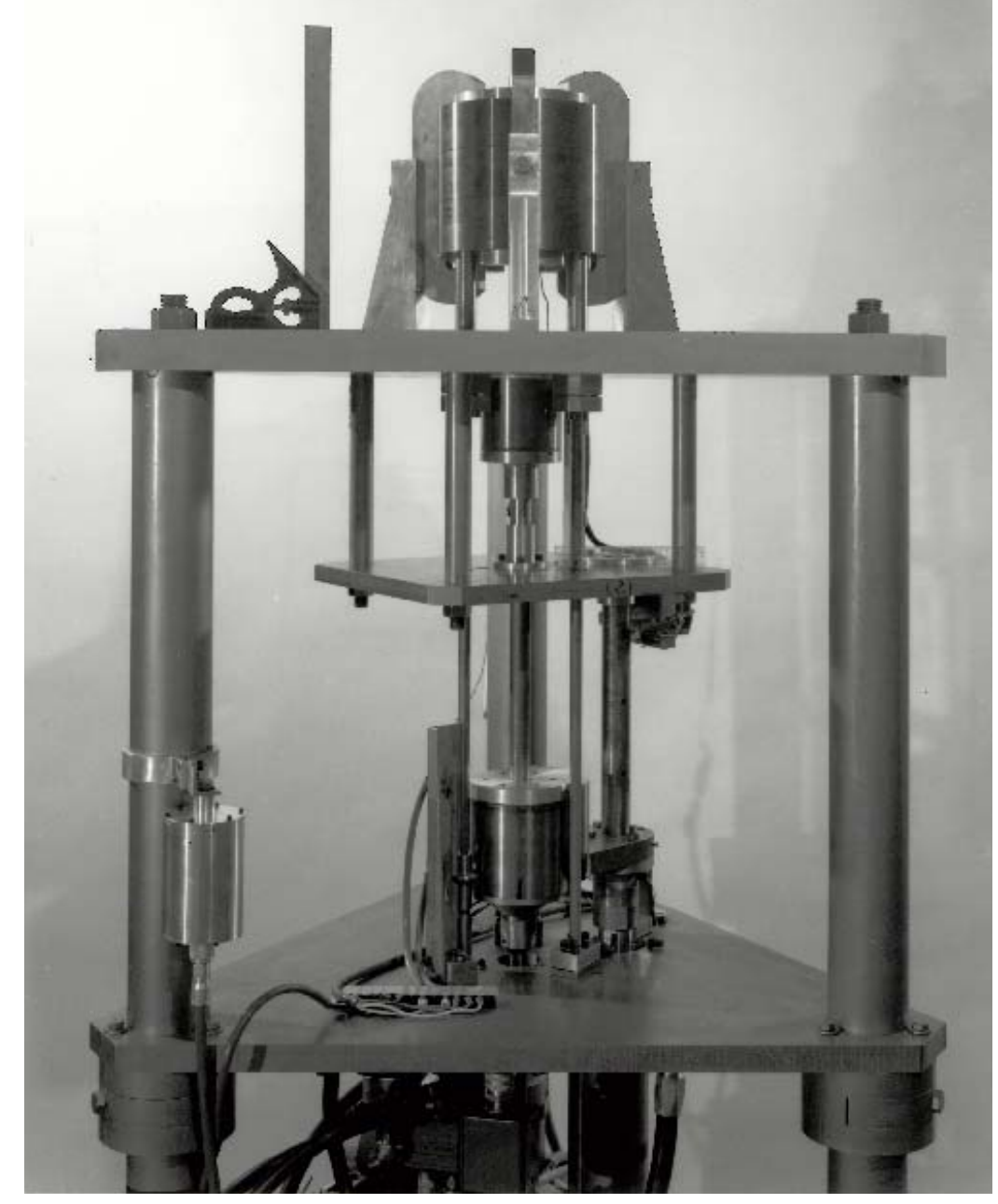

- Cylindrical geometry core design.

- Dimensions of 7 in. in diameter $(17.8 \mathrm{~cm}) \times 6$ in. tall $(15.2 \mathrm{~cm})$.

- Uranium-molybdenum alloyed metal (1.5 wt \% molybdenum).

- Core mass of $\sim 66 \mathrm{~kg}$.

- Uranium content enriched to 93.5 wt $\%{ }^{235} \mathrm{U}$.

Godiva IV assembly, circa 1967. 


\section{Godiva IV Assembly Description (EO1)}

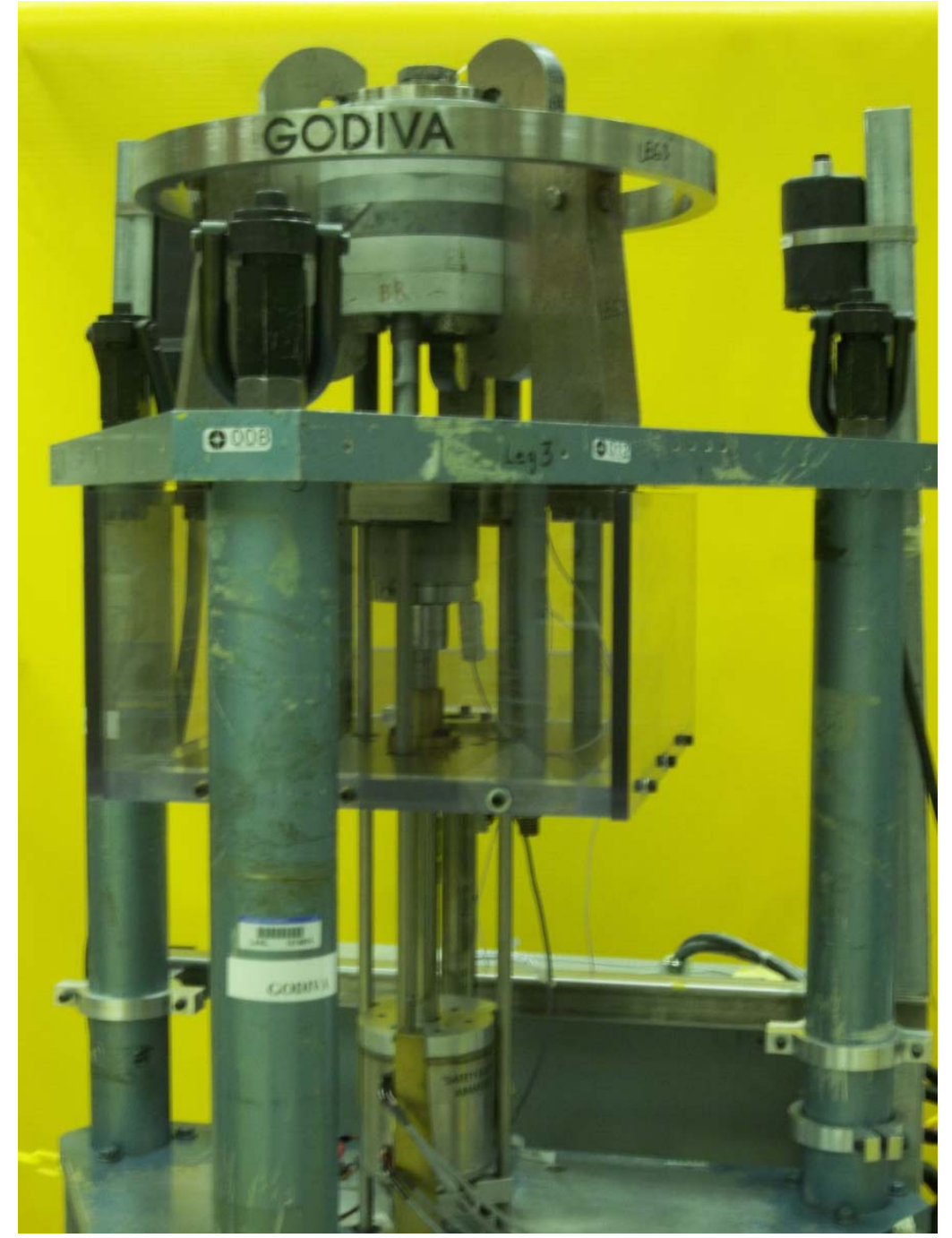

- Operations performed in the subcritical, delayed-critical, and prompt-critical regimes.

- Theoretical maximum burst with a temperature rise of $525^{\circ} \mathrm{C}, \mathrm{FWHM}$ of $25 \mu \mathrm{s}$, is equivalent to 90,000 $\mathrm{MW}_{\text {th }}$.

- Current applications include

- sample reactivity worth studies,

- reactor kinetics benchmark studies,

- reactor dynamic excursion studies,

- sample neutron activation studies,

- dosimetry measurements,

- criticality alarm testing,

- critical assembly operator training, and

- criticality safety training demonstrations. 


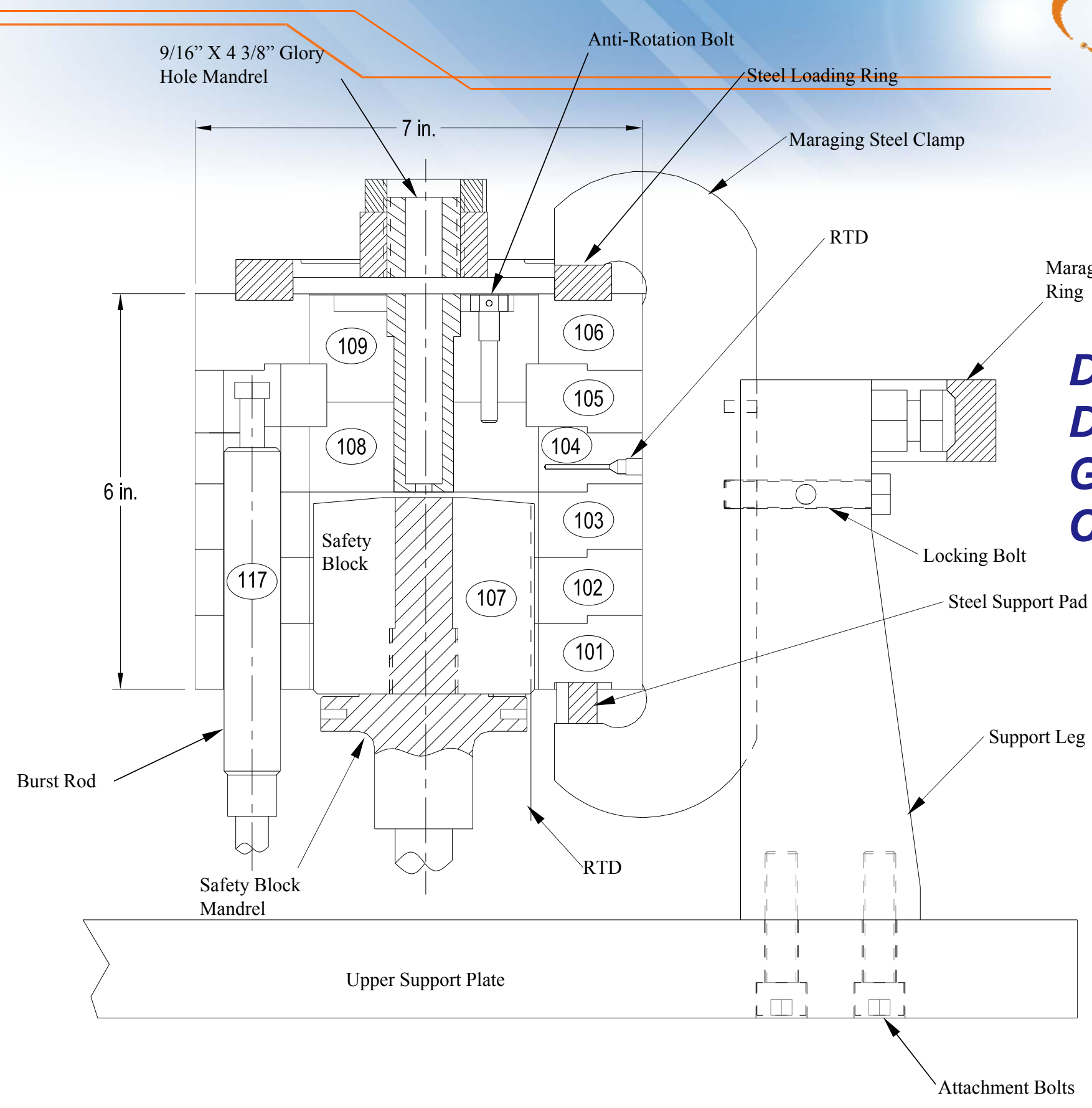

araging Steel Compression

Detailed Design

Drawing of

Godiva IV

Core (E01)

Safety Block

Mandrel

Upper Support Plate 


\section{Godiva IV Mechanical Systems (EO1,EO5)}

- Safety Block Drive Mechanism

- Hydraulic pump package with integral three-way valve

- Hydraulic system lifts, lowers, or holds stationary the safety block electromagnet

- An energized electromagnet lifts the rod attached to the safety block

- Control Rod Drive Mechanism

- Stepper motors operated at single speed

- Control rods back-drive when power removed from stepper motors

- W-Cu weights increase back-drive speed

- Burst Rod Mechanism

- Pneumatic system with two-way valve

- Pressure provided by air compressor 


\section{Godiva IV Control System (EO1,EO5)}

- Programmable Logic Controller (PLC)

- Allen-Bradley PLC-5

- Stores program files and a data table, reloaded from EEPROM on power-up

- Allen-Bradley modules for $\mathrm{I} / \mathrm{O}$, communication, control, sensors

- Located in Control Room
- Human Machine Interface (HMI)

- RSView software with multiple files stored as a project

- Located on Control Room and Local HMI computers

- Identical, except for comm checks between $\mathrm{HMI}$ and PLC

- Both share data with PLC data table 


\section{Godiva IV HMI Display (EO1, EO5)}

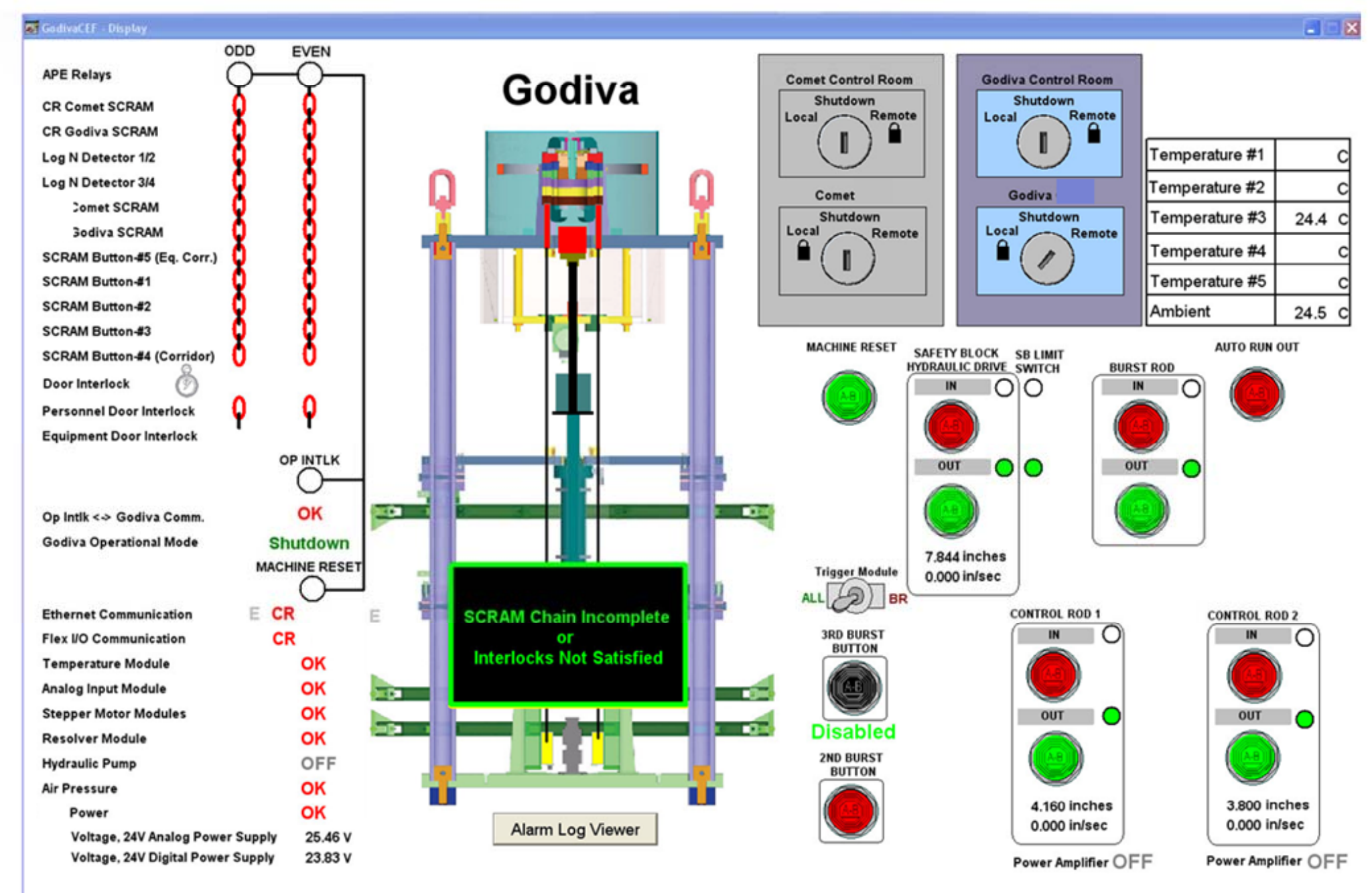




\section{Control System Interlocks (EO1,EO5)}

\section{Dead-Man Feature}

- Releasing a button will stop the motion of the control element.

When operating in Remote:

- The Safety Block must be on in limit before Control Rod 1 and/or 2 can be inserted.

- All elements must be on out limit before reset is allowed.

When operating in Local:

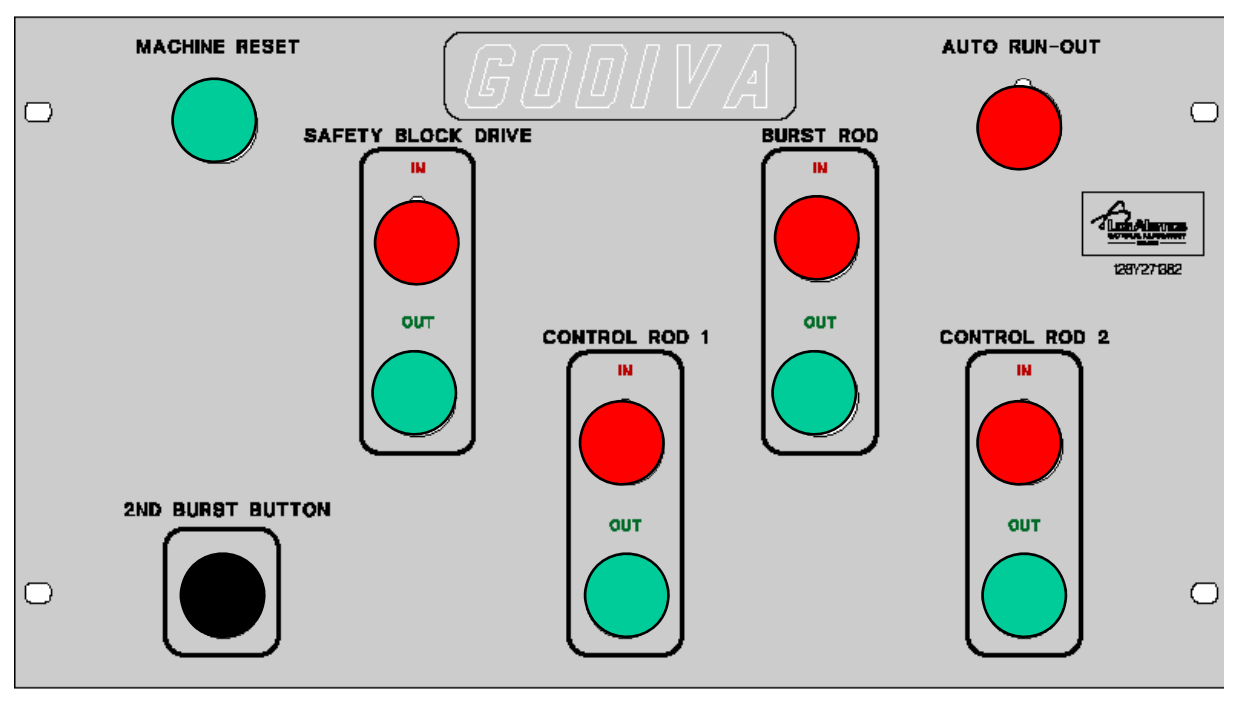

- Only one element may be moved from out limit at a time.

- All elements must be on out limit before reset is allowed. 


\section{Burst Rod Interlocks (EO1,EO5)}

When operating in Remote:

- The burst rod can be inserted by one operator if the Safety Block is on in limit and both Control Rods are on their out limits.

- The burst rod can be inserted by two operators if the Safety Block is on in limit and both Control Rods are not on their out limits.

When operating in Local:

- The burst rod can be inserted by one operator if the Safety Block is on its out limit and both Control Rods are on their out limits.

- There is no second burst button on the Local panel. 


\section{Control Rod Integral and Inverse Differential Worths (EO1,EO5)}

Control Rod Integral Worth

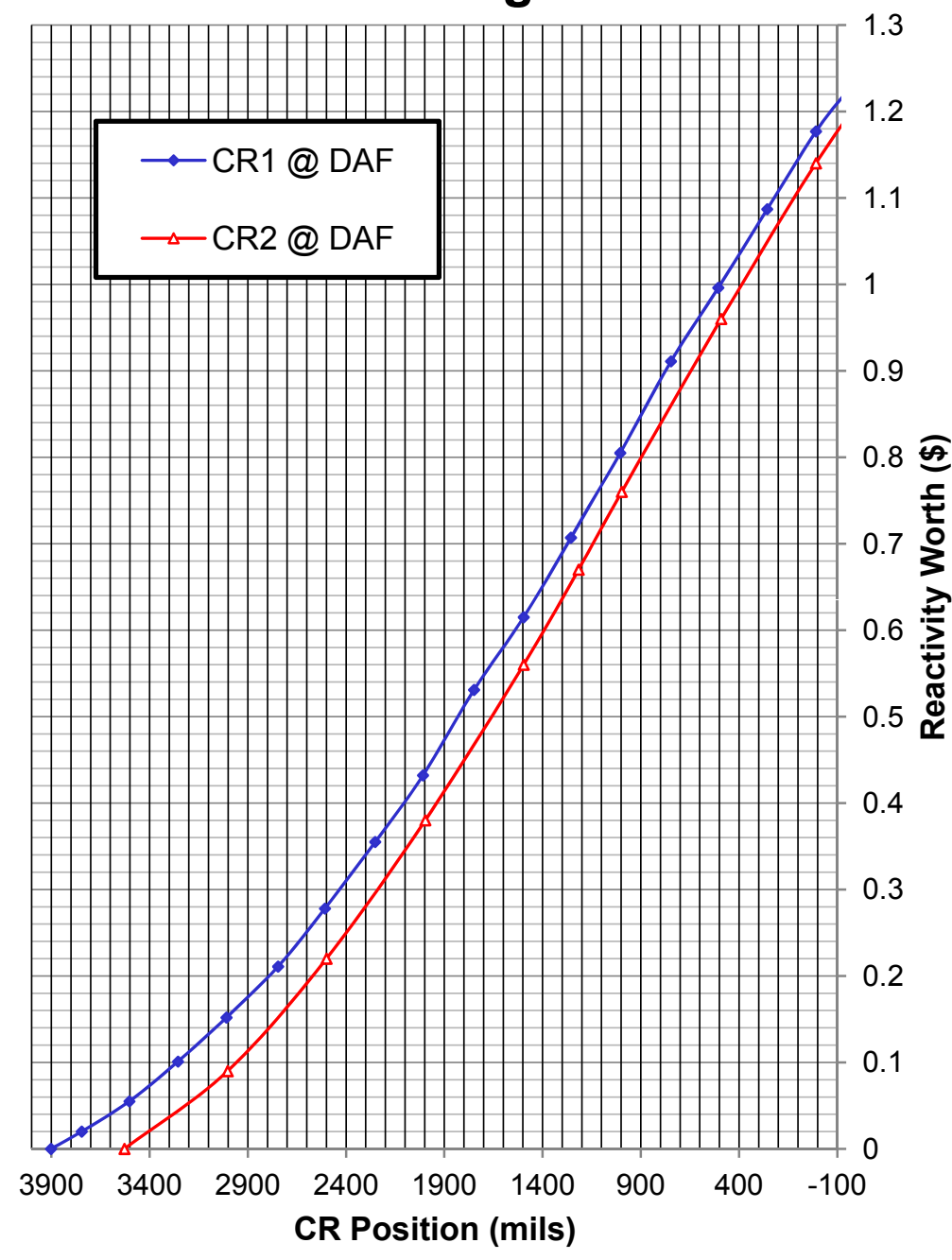

Control Rod Inverse Differential Worth
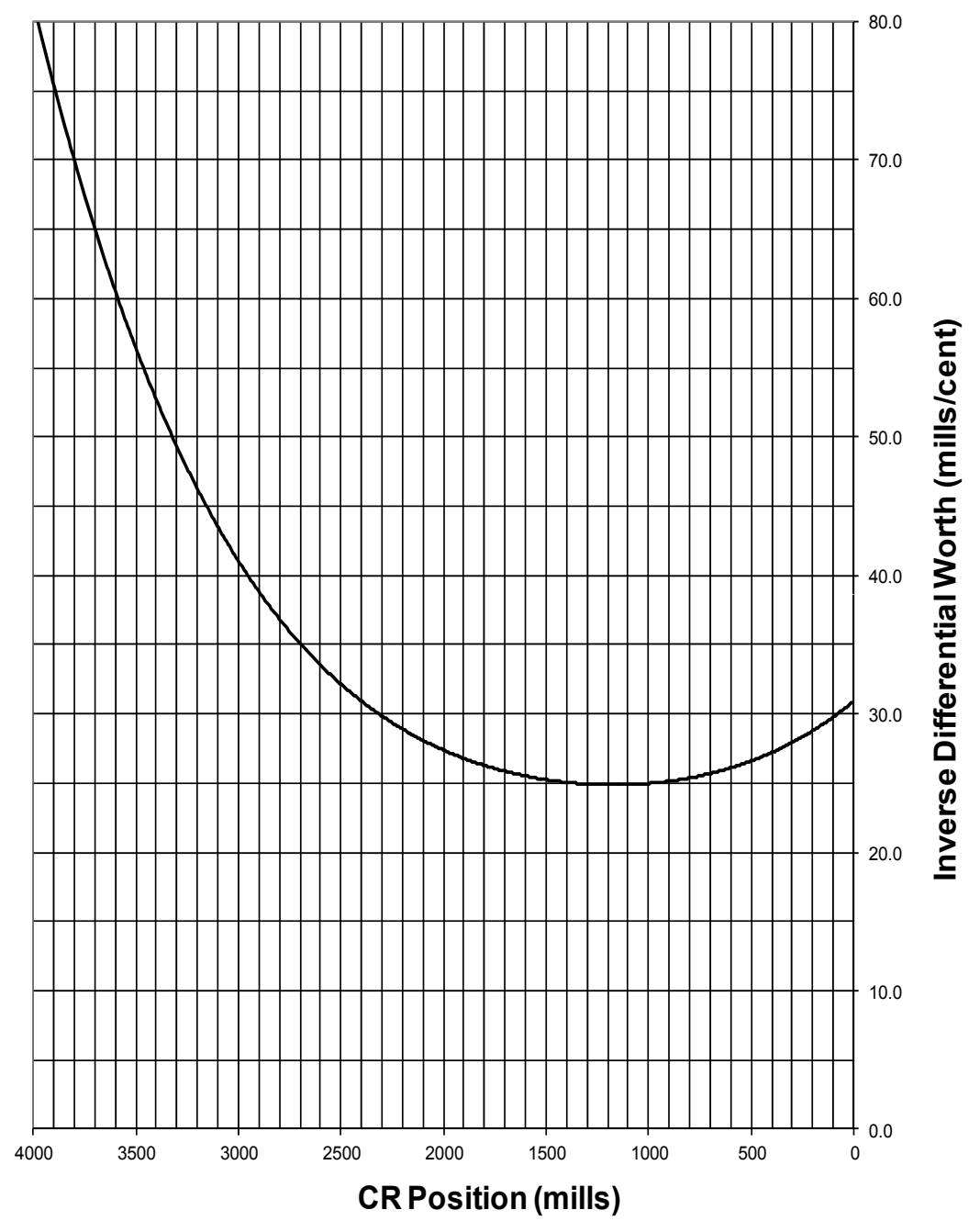


\section{Inhour Equation ${ }^{4}$ for the Godiva IV Assembly (EO2)}

$$
\rho(\$)=\frac{l}{\beta_{e f f} * T}+\sum_{i=1}^{6} \frac{\beta_{i} / \beta_{e f f}}{1+\lambda_{i} T}
$$

where

$\rho(\$)$ is the reactivity in dollars

$\beta_{\text {eff }} / 1$ is the Rossi- $\alpha$ at delayed critical

$T \quad$ is the reactor period

$\beta_{\mathrm{i}} / \beta_{\text {eff }}$ is the relative abundance for ${ }^{235} \mathrm{U}$ for each of the six groups from fast fission

$\lambda_{i} \quad$ is the decay constant for ${ }^{235} U$ for each of the six groups from fast fission 


\section{Parameters 4 Needed for the Inhour Equation (EO2)}

For the Godiva IV assembly:

$$
\alpha(\mathrm{DC})=\beta / 1=1.1 \times 10^{6} \mathrm{~s}^{-1}
$$

Decay Constants and Yields for ${ }^{235} \mathrm{U}$ from Fast Fission

\begin{tabular}{|c|c|c|}
\hline $\begin{array}{c}\text { Group } \\
\text { Index, } \mathrm{i}\end{array}$ & $\begin{array}{c}\text { Decay Constant } \\
\lambda_{\mathrm{i}} \mathrm{s}^{-1}\end{array}$ & $\begin{array}{c}\text { Relative Abundance } \\
\mathrm{a}_{\mathrm{i}}=\beta_{\mathrm{i}} / \beta_{\text {eff }}\end{array}$ \\
\hline 1 & 0.0127 & 0.038 \\
\hline 2 & 0.0317 & 0.213 \\
\hline 3 & 0.115 & 0.188 \\
\hline 5 & 0.311 & 0.407 \\
\hline 6 & 1.40 & 0.128 \\
\hline
\end{tabular}




\section{Graphical Representation of the Inhour}

\section{Equation for the Godiva IV Assembly (EO2)}

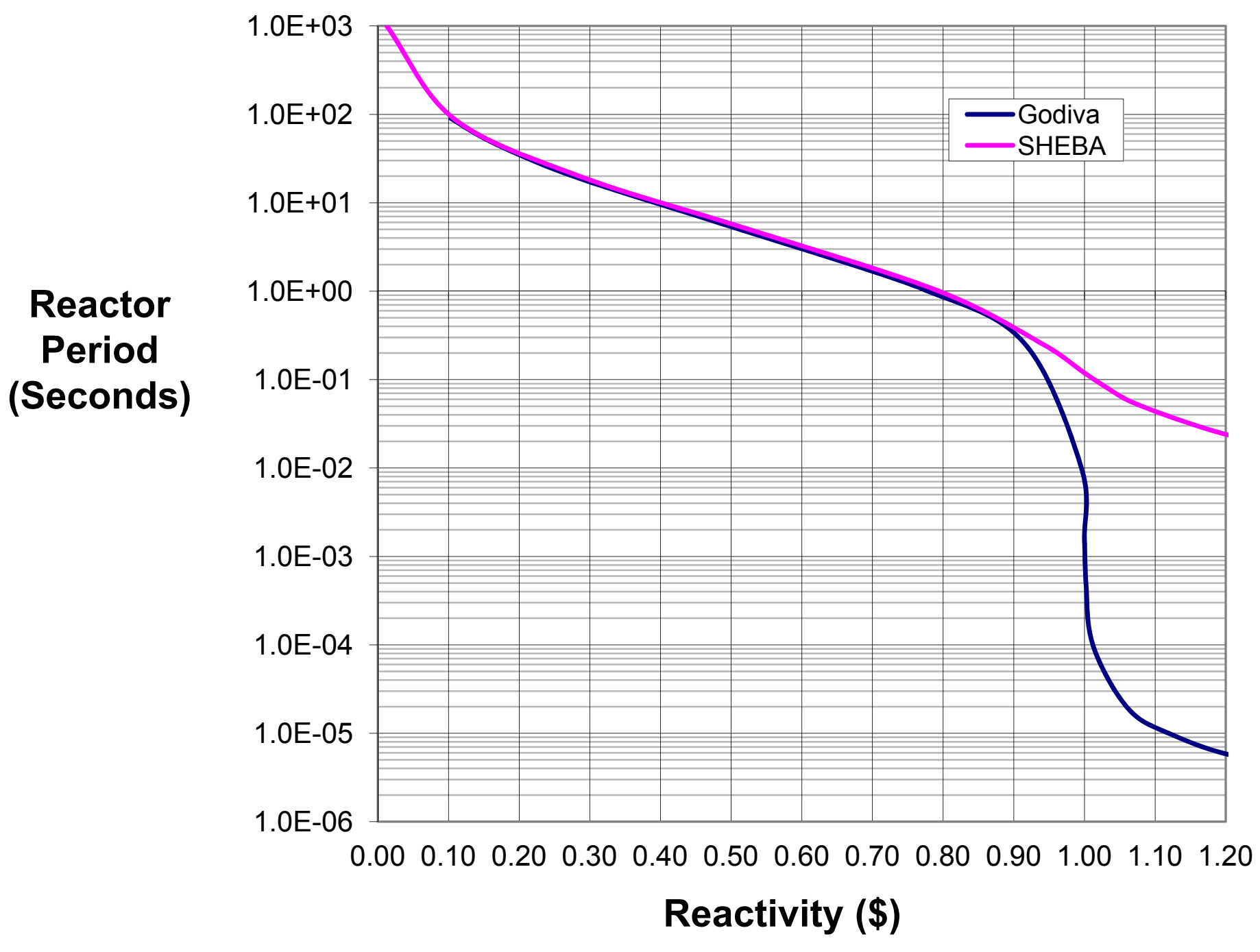




\section{Delayed Critical and Prompt Critical (EO3)}

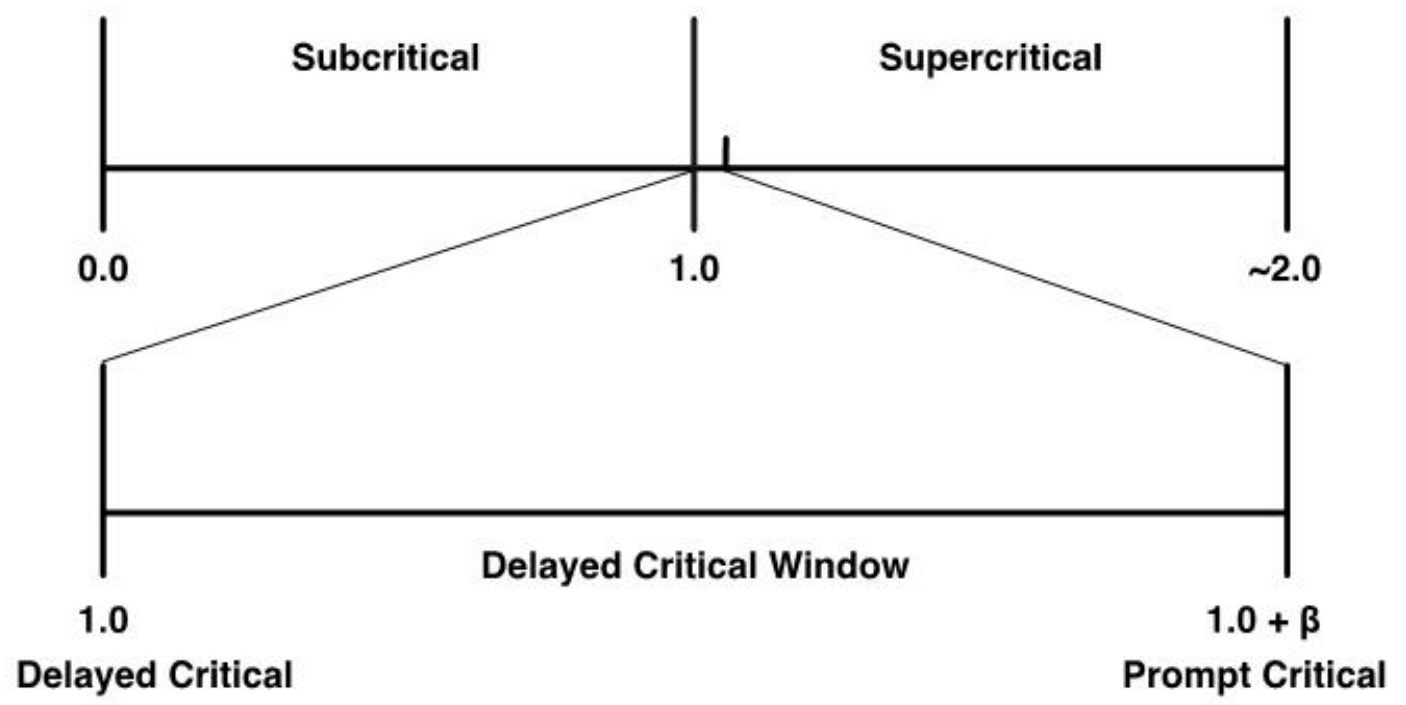

Reactivity itself is unitless

However, it can be quoted in units of:

Dollars and cents

pcm (percent millirho)

Take the Delayed Critical Window $(0<\rho<\beta)$ and split that interval into 100 units (called cents)

One dollar is 100 cents

By definition, $\$ 1.00$ of reactivity is prompt critical 


\section{Delayed Critical and Prompt Critical (EO3)}

- Delayed Critical Reactor needs both delayed and prompt neutrons to be a self-sustaining neutron chain reacting system.

- Increase in neutron population (power) dominated by the timescales associated with the appearance of delayed neutrons (neutrons from fission product decay with half lives on the order of milliseconds to minutes).

- Longer timescales DO allow for control mechanisms to affect the transient power behavior (control rods, mechanical safety systems, operator intervention, etc.) 


\section{Delayed Critical and Prompt Critical (EO3)}

- Prompt Critical: Reactor needs only prompt neutrons to be a self-sustaining neutron chain reacting system.

- Increase in neutron population (power) dominated by the timescales associated with the appearance of prompt neutrons (nanoseconds to milliseconds).

- Shorter timescales DO NOT allow for control mechanisms to affect the transient power behavior. 


\section{Temperature Coefficient of Reactivity (EO4)}

$$
\frac{\Delta \rho}{\Delta T}\left(\phi /{ }^{\circ} \mathrm{C}\right)
$$

Negative - temperature reactivity quench

Positive - autocatalytic or divergent reaction

\begin{tabular}{|l|l|}
\hline Assembly & Approx. Temp. Coeff. \\
\hline Godiva IV, Big Ten, Flattop U & $-0.3\left(\phi /{ }^{\circ} \mathrm{C}\right)$ \\
\hline Flattop delta-phase plutonium & $-0.2\left(\phi /{ }^{\circ} \mathrm{C}\right)$ \\
\hline SHEBA U $(5)$ solution & -4.0 to $-10.0\left(\phi /{ }^{\circ} \mathrm{C}\right)$ \\
\hline $\mathrm{CNPS}\left(\mathrm{U}(20) \mathrm{O}_{2}-\mathrm{C}\right.$ matrix & $-1.2\left(\phi /{ }^{\circ} \mathrm{C}\right)$
\end{tabular}

Contributions from expansion, Doppler shifts, geometry changes 


\section{Temperature Coefficient of Reactivity for Godiva}

(EO4)

Reactivity versus Average Temperature

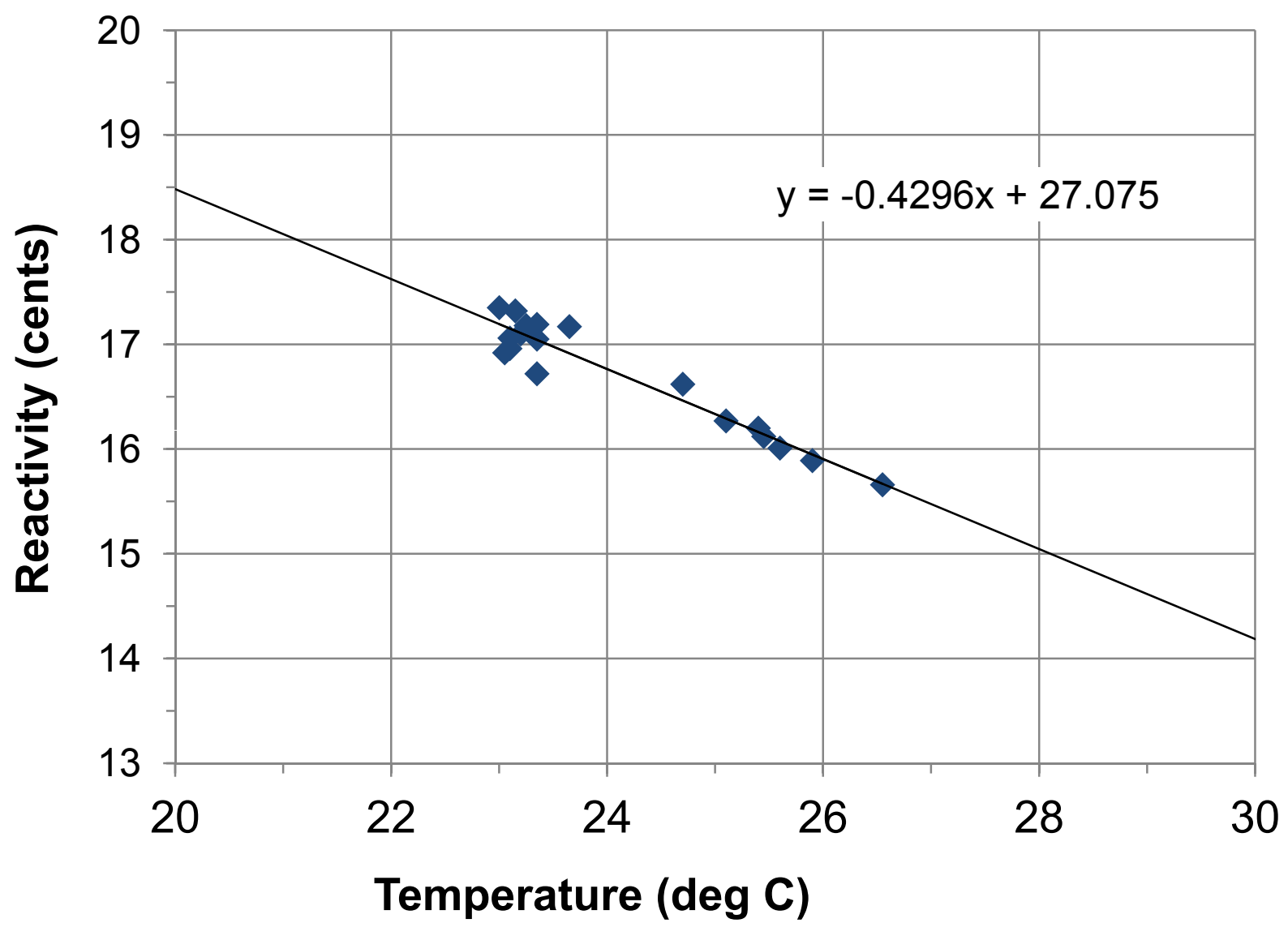




\section{Godiva IV Operation (EO3,EO5)}

1. Control Room OSS placed in Remote (key is captured)

a. Lights go steady and horn sounds for $30 \mathrm{~s}$

b. Press Reset

2. Delayed Critical Operation

a. Safety Block inserted

b. Insert Control Rods to 1.000 in., 1.000 in. (wait)

c. Insert Control Rods to $0.500,0.500$ (wait $1-5$ min to verify at or below $\mathrm{DC})$

d. Insert Control Rods to 0.000, 0.500 (wait until neutrons are observed)

e. Insert Control Rods to $0.000,0.000$; record in positions

f. Measure period to determine excess reactivity 


\section{Burst Operation (EO3,EO5)}

Continuing from previous steps

3. Prompt Critical Operation

a. Move Control Rod 2 out to 0.350 , then back in to 0.250

b. Find DC with Control Rod 1 (maintain for one full linear channel screen)

c. Insert burst increment with Control Rod 2

d. (nominally 95 mils for $70^{\circ} \mathrm{C}$ burst, 150 mils for $100^{\circ} \mathrm{C}$ burst)

e. Retract safety block 2-5 in.

f. Wait 15-20 minutes

g. Arm instrumentation, O'scope, trigger module

h. Insert safety block, then immediately burst rod (requires both crew members)

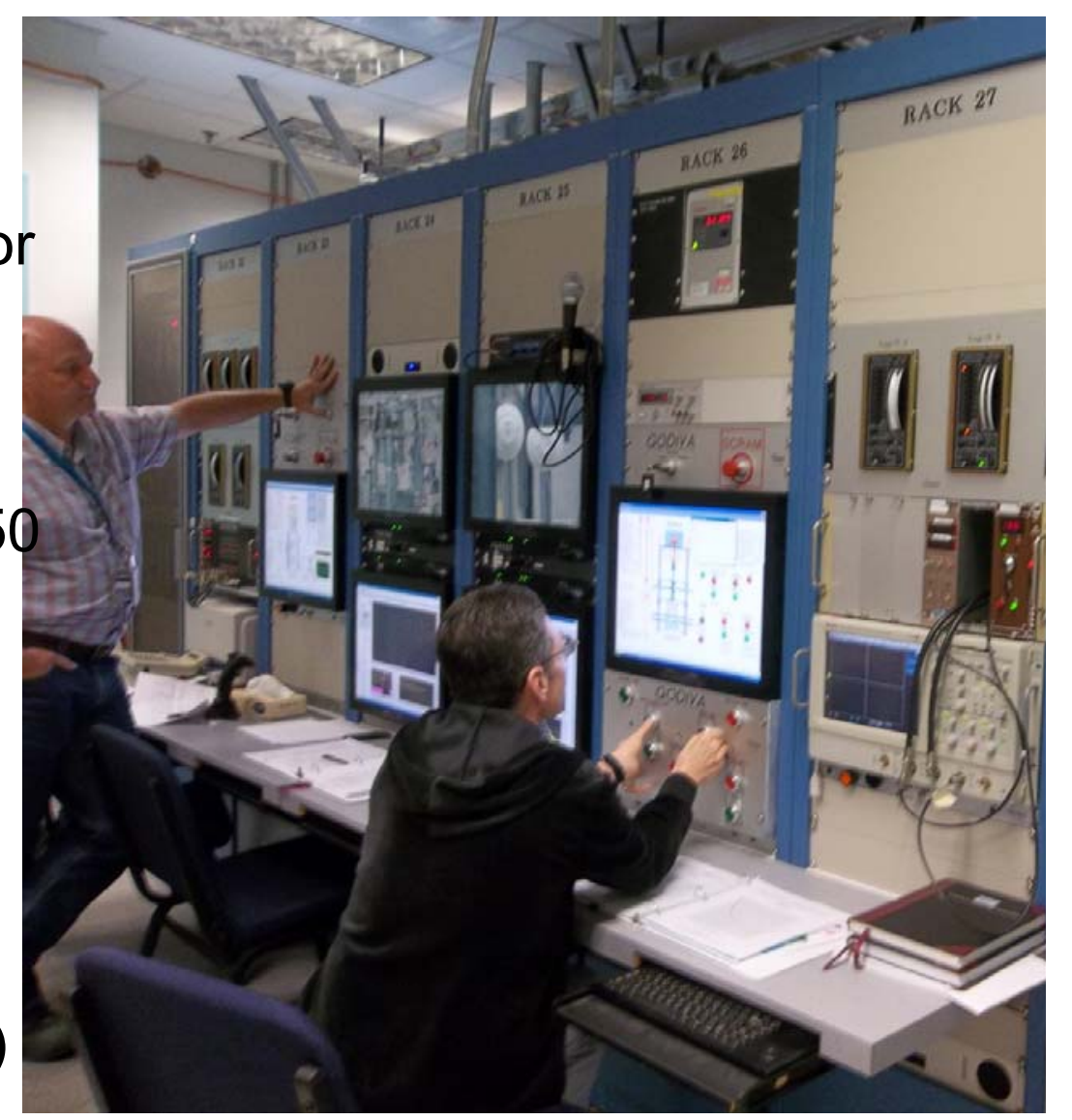




\section{Godiva IV Operation (EO3,EO5)}

\section{NGSP

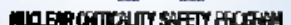

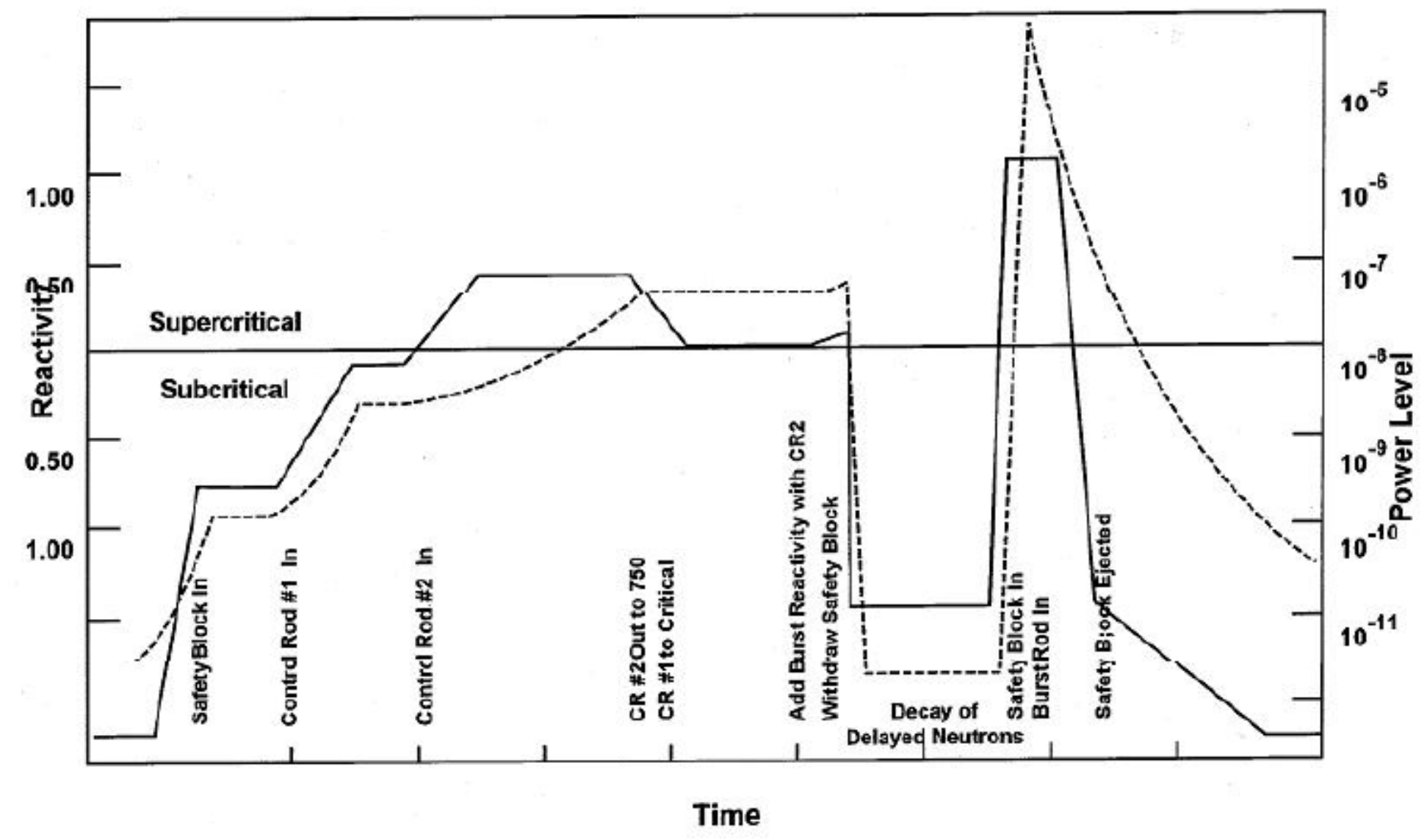




\section{Burst Occurs}

\section{NESP}

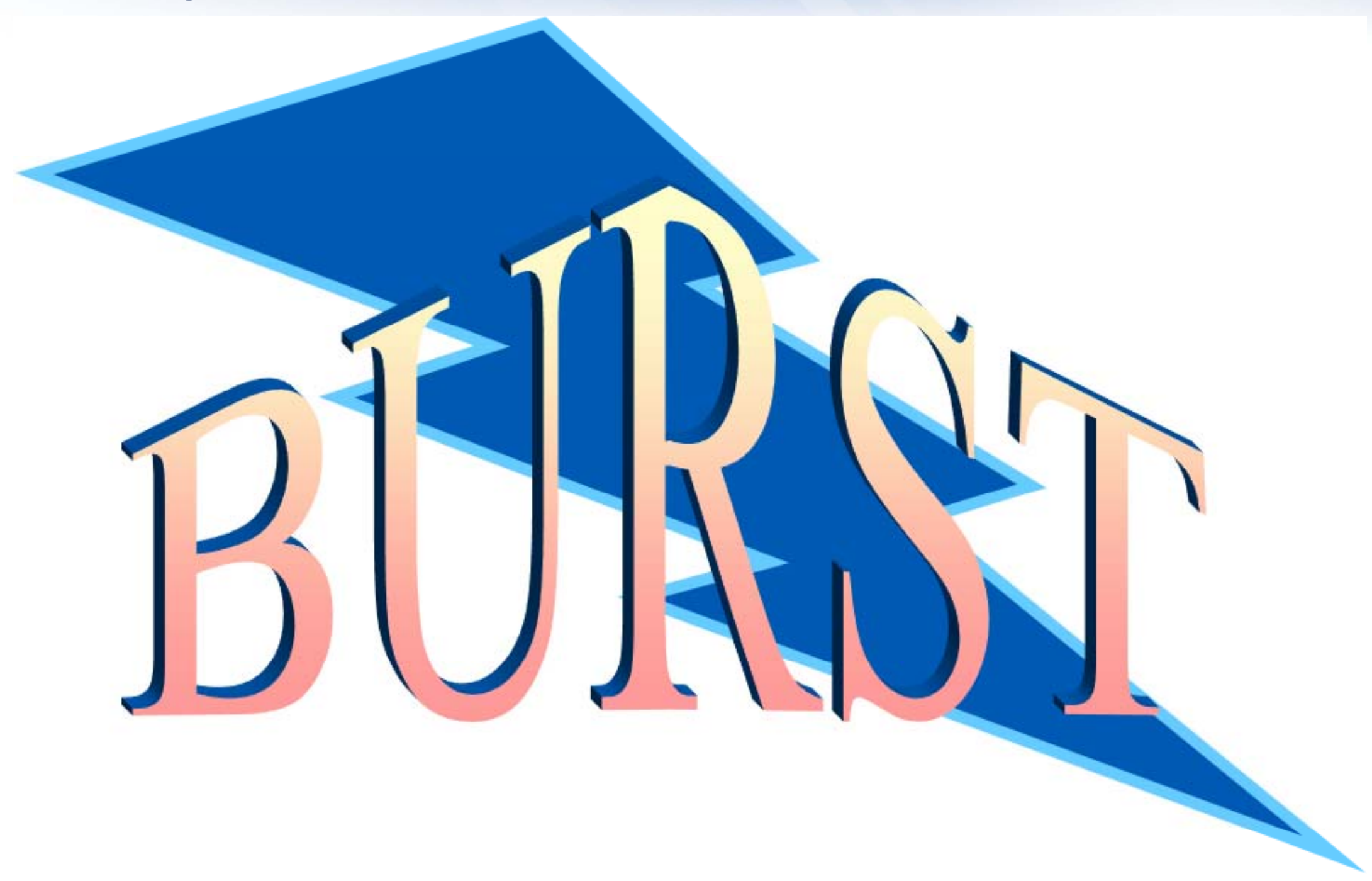




\section{What Terminates the Burst? (EO1,EO3,EO4,EO5)}

- Expansion and Neutron Leakage

- Shock Wave Removal of Safety Block

- Trigger Module Input to Control System

- Log-N SCRAM Signal

When the PMT signal (1) exceeds a threshold, the trigger signal (3) sends input to the control system and O'scope to capture PD signal (2).

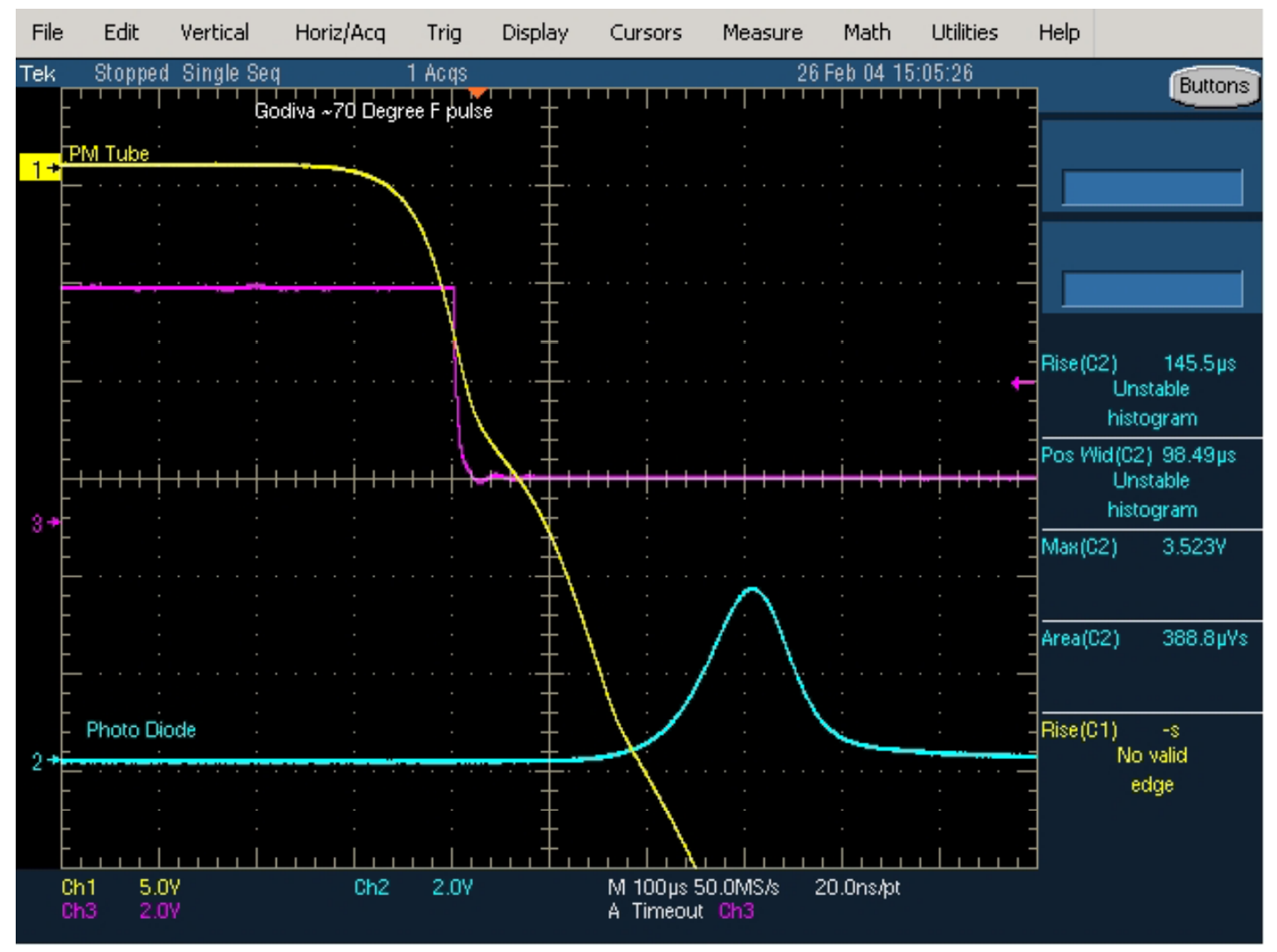




\section{Burst Data (EO3,EO5)}

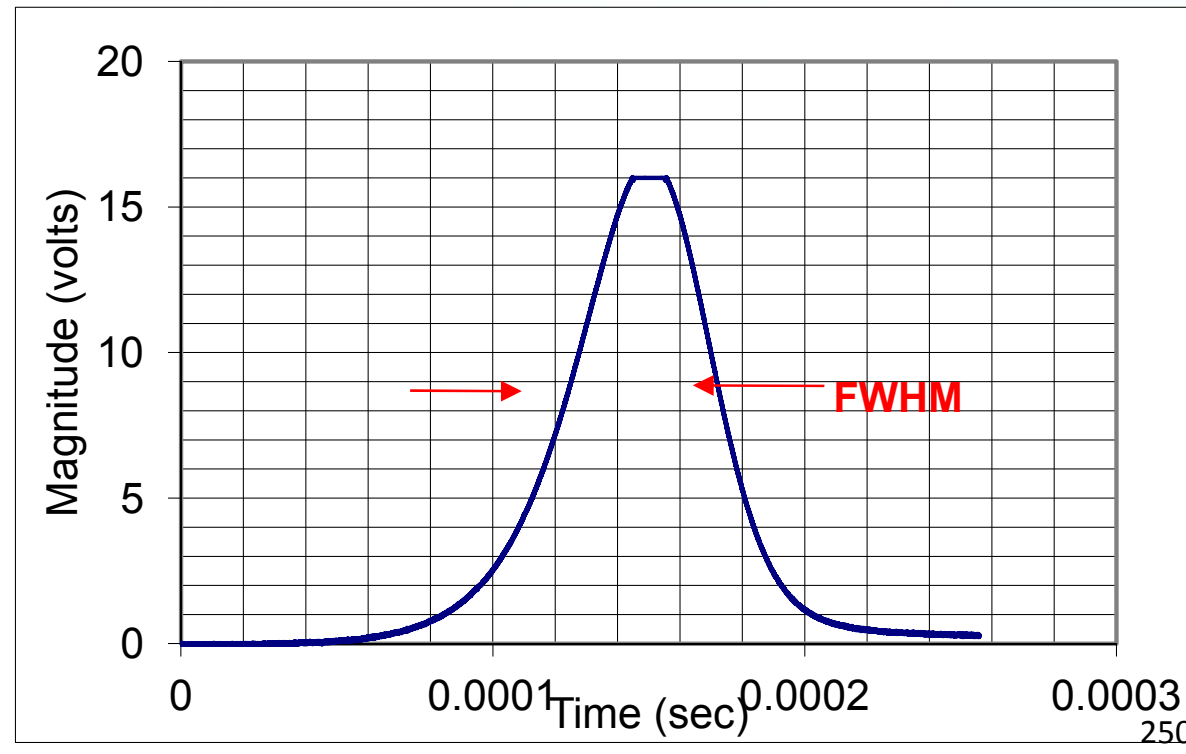

\section{PD signal for $150^{\circ} \mathrm{C}$}

RTD data for $200{ }^{\circ} \mathrm{C}$ burst

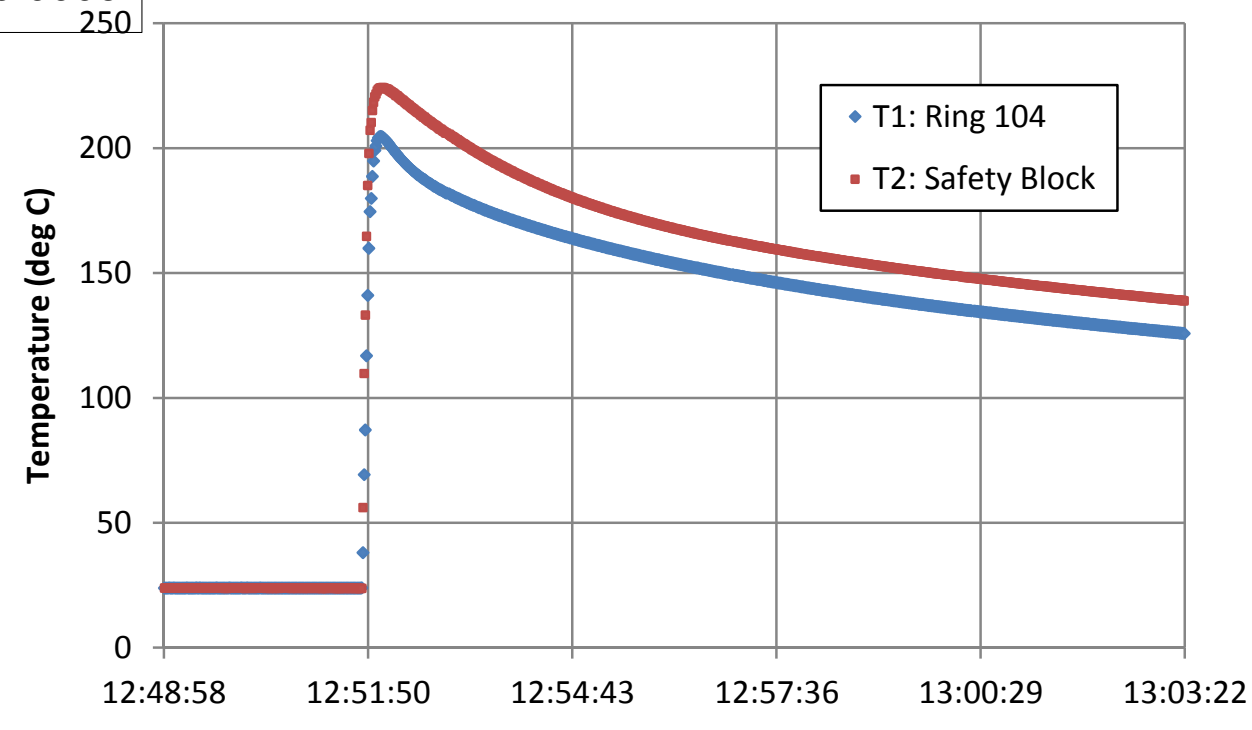




\section{Dosimetry}

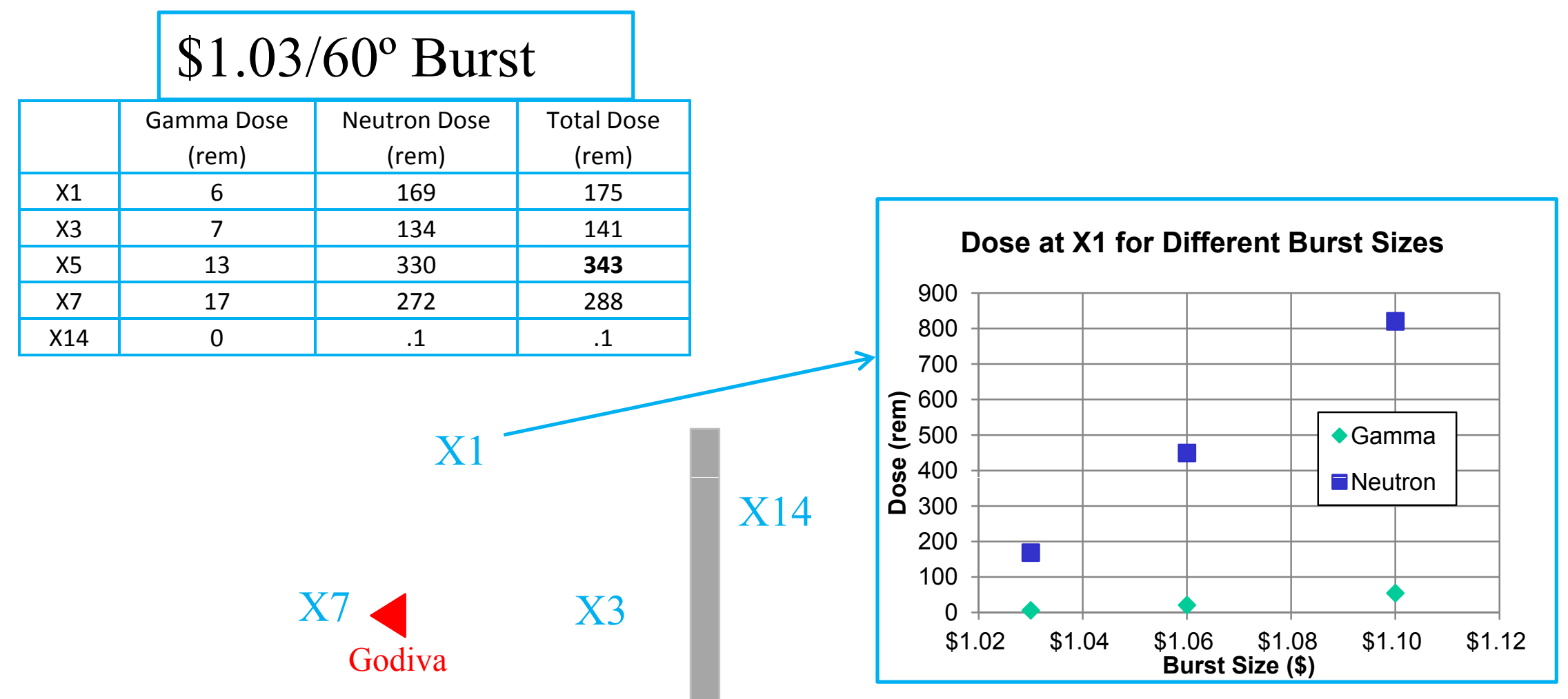




\section{References}

1. R. R. Paternoster et al., "Safety Analysis Report for the Los Alamos Critical Experiments Facility (LACEF) and the Hillside Vault (PL-26)," Los Alamos National Laboratory report LA-CP-92-235, Rev. 4 (1998).

2. T. F. Wimett, R. H. White, and R. G. Wagner, "Godiva IV," Proceedings of the National Topical Meeting on Fast Burst Reactors, Albuquerque, NM, pp. 95-104 (January 1969).

3. R. D. Mosteller and J. M. Goda, "Analysis of Godiva-IV DelayedCritical and Static Super-Prompt-Critical Conditions," presented at the International Conference on Mathematics, Computational Methods, and Reactor Physics, Saratoga Springs, NY (May 2009).

4. G. R. Keepin, Physics of Nuclear Kinetics, Addison-Wesley Publishing Company, Inc., Reading MA (1965). 